\title{
Space station light show sparks aurora riddle
}

Tony Reichhardt, Washington

Astronaut Ed Lu returned last Monday from a six-month tour as science officer on the International Space Station with many memories and at least one nagging puzzle: what caused the mysterious flashes of light he saw while studying Earth's aurora from orbit?

$\mathrm{Lu}$, who was an astrophysics researcher before becoming an astronaut in 1994, estimates that he spent 100 hours watching the northern and southern lights during his half-year in space. The auroral light show, which takes place well below the station's 380-kilometre altitude, shimmers and pulses depending on natural variations in incoming solar particles trapped by Earth's magnetic field.

On three occasions - 11 July, 24 September and 12 October — Lu saw something markedly different: flashes as bright as the brightest stars, which lasted only a second and then blinked off again. In one instance, he called crewmate Yuri Malenchenko over to the window, and he saw the bursts too.

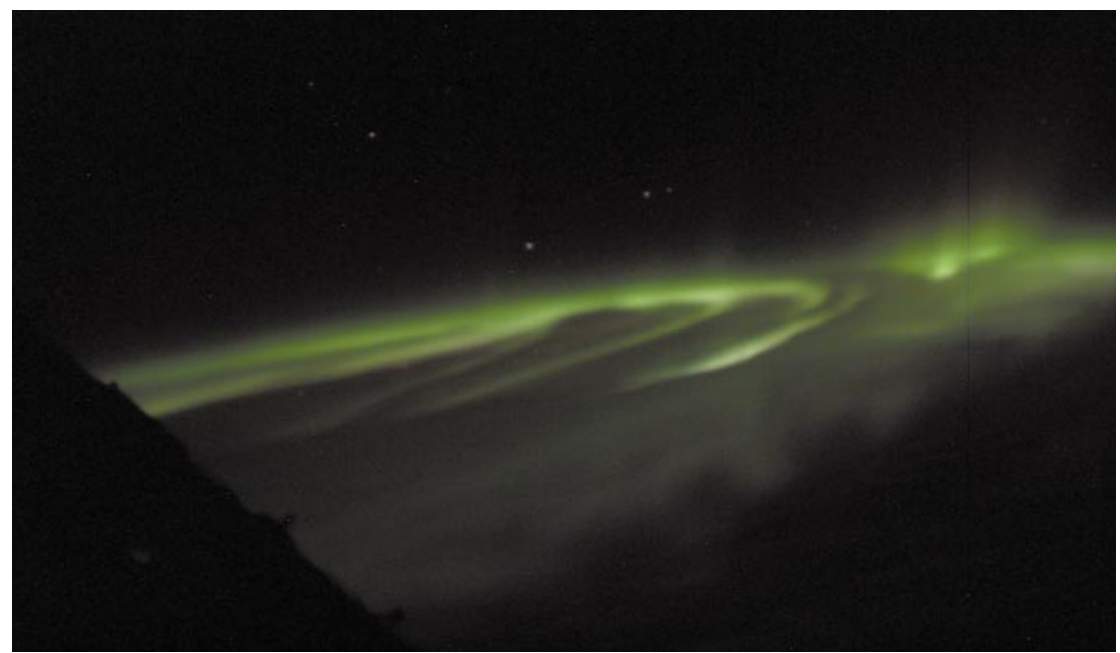

Like a flash: astronaut Ed Lu's usual view of Earth's aurora (above) was punctuated by mystery flares.

Lu says that they were very different from the random but harmless retinal flashes that many astronauts experience when heavy cosmic rays hit their eyeballs.

Given his limited time and ability to research the problem in space, $\mathrm{Lu}$ has tried to rule out other obvious explanations. The flashes didn't look like sunglint from dust particles outside the station, which rotate and last longer than a second. Nor were they meteors, which look like linear streaks. Viewing conditions were wrong for a satellite or other artificial object — the flashes only appeared in the direction of the aurora. And Lu checked weather maps, which showed no lightning storms below at the time of his observations. All of which leads him to the tentative conclusion that he was seeing a previously unreported phenomenon associated with the aurora.

Speaking to Nature by telephone from the space station, the astronaut said that his postlanding duties would probably keep him from attacking the problem for several months after his return. He has already had e-mail discussions with aurora specialists on the ground, however, and has yet to discover any previous satellite or astronaut report of similar optical bursts. Even though it wasn't a planned experiment, the scientist in Lu hopes to find an explanation: "It's a good thing to get out in the open, so that people who do know more can start to think about it."

\section{Democrats condemn government 'meddling' with $\mathrm{NIH}$}

\section{Erika Check, Washington}

Is the fire department at the National Institutes of Health (NIH) essential to the agency's core mission? And what about its grant support staff? The Bush administration's suggestion that these and thousands of other NIH jobs might be contracted out to the private sector is drawing fire from Democrats in Congress.

"The scientific mission [of the NIH] is at risk because of a misguided privatization plan that meddles with scientists, opens the door to unnecessary security threats, and seriously undermines morale and productivity," says a 20 October letter to administration officials, signed by Representative Henry Waxman (Democrat, California) and four senators and congressmen from Maryland, where the NIH is based.

The letter was addressed to Joshua Bolten, chief of the White House budget office, and Tommy Thompson, head of the Department of Health and Human Services, to which the NIH belongs. It criticizes a government-wide initiative that asks agencies to determine which of their jobs might be done more efficiently by the private sector, and then initiate competitions with private bidders to determine who will do a better and cheaper job. The Bush administration is committed to the competitions, but they have worried some government scientists, who say that research

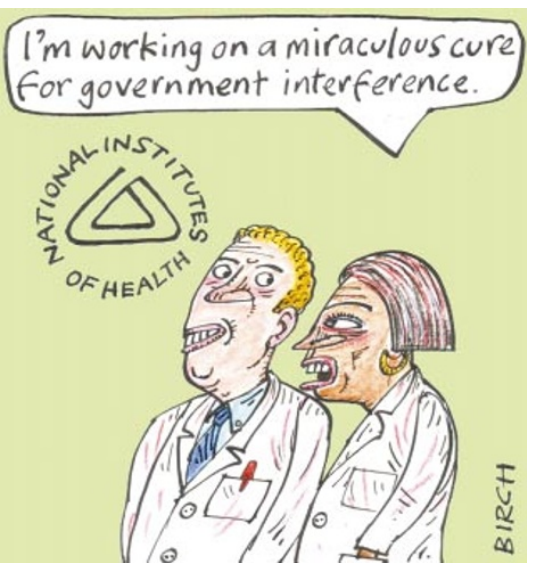

agencies require skills that are not available from outside (see Nature 424, 478; 2003).

Waxman's letter says the competitions are draining resources and hampering the NIH's core mission. It adds that the agency is spending \$15 million on job reviews, and that NIH employees have already spent 100,000 hours preparing for competitions. The agency also plans to put some 4,000 jobs — including some scientific roles - up for bidding by 2005 , the letter claims.

Health department spokesman Bill Pierce says Thompson is merely trying to ensure that the government saves as much money as possible. "Very few people would say it would not be a worthy goal for the NIH to do things more efficiently," Pierce adds.

Pierce says the government has to ensure that federal dollars are well spent. The NIH, Pierce notes, has won both competitions held this year, and will therefore retain its grant-support staff and infrastructure managers. "For the NIH to be doing its job better and more efficiently, but still within the NIH, is very positive," he says. 